\title{
The Influence of Blasting Energy Factor on the Loading Performance
}

\author{
Paulo Couceiro \\ Advanced Application Solutions \\ MAXAM \\ Madrid, Spain
}

\author{
Bruno Santos \\ Technical Application Department \\ MAXAM \\ Singapore
}

\begin{abstract}
This paper explores the influence of rock blasting fragmentation on the performance of loading equipment in open pit mining applications. Since the efficiency of unit operations is becoming important for long term mining strategies, costeffective approaches are required to increase mine productivity. In this sense, the performance of downstream operations, such as the loading of blasted materials, is potentially influenced by the energy content in the blasting phase. Rock fragmentation, muckpile shape and swelling are key factors for an efficiency excavation. Hence, a special case study from a relevant gold mine in South America is presented, where benefits of a high energy blasting strategies has been proved to deliver important downstream benefits.
\end{abstract}

\section{Keywords—Blasting, loading performance, digging rate}

\section{INTRODUCTION}

The main purpose of blasting is to achieve of an adequate rock particle size distribution in order to optimize downstream operations. Numerous aspects suggest blasting as an attractive tool of optimization. The first of them is the fact that it is the lowest energy cost when compared with others downstream costs [1]. In addition, changes in explosives and blasting practices involve low investment and transition time, a part of being easier to implement than in other processes, such as loading and haulage or crushing and milling.

The consecutive unit operation after blasting is normally the loading and haulage operations. In this step, the digging performance, in what correspond to the blast results, is directly influenced by the fragmentation size distribution, shape and swelling of the muckpile. Although there are other important factors influencing the overall performance of loading and haulage, such operator's skills, floor and weather conditions, and others, specific studies have proven the impact of blasting on these operations [2, 3, 4, 5].

The evaluation of blasting performance on the pit is usually carried out by the degree of rock fragmentation and excavators' efficiency $[6,7,8]$. Since to obtain a representative fragmentation curve is time-consuming, the performance of loading operations is commonly used as an indicator of the quality of the blasted muckpile. In this sense, digging rate or digging time are indicators of the loading operation and can be easily monitored with on-line system or video measurements $[2,8,9]$.

Thus, in this paper, the influence of different explosives' energy, through the energy factor, is evaluated in terms of fragmentation and loading performance.

\section{EXPERIMENTAL DATA AND METHOD}

One important open pit mine operation, responsible for $22 \%$ of the Brazilian gold production, was increasing their production capacity and inventory under a strong environment commitment. In an effort to improve downstream efficiencies and productivity, a technical and economic study were carried out in order to evaluate the potential impact of a highly energetic watergel in comparison with the traditional emulsion in downstream operations without disturbing the current safety and environment scenario.

A comparative study with 20 shots was carried out. All these blasts were performed using the same blast parameters such as drilling pattern, diameter, stemming, explosive average density and powder factor. Benches with similar geological and geotechnical properties, with Work Indexes varying from 7.7 to 14.2 , were divided in two areas, one charged with watergel and another charged with the traditional emulsion, both blended with $30 \%$ of ANFO, as shown in Figure 1. These conditions ensure the similar application conditions for both explosives.

The heat of explosion at a constant volume of the watergel was $3.44 \mathrm{MJ} / \mathrm{kg}$ while the emulsion was $3.01 \mathrm{MJ} / \mathrm{kg}$. Specific KPIs were established in order to proper compare the performance of both explosives downstream: ground vibration and air overpressure, fragmentation and loading efficiency.

Although the impact on all the other subsequent unit operations are needed to have a complete overview of blasting performance, the instantaneous digging rate are still one of the best methods to evaluate the quality of the macrofragmentation in mining operations [2].

The analysis of loading performance on both watergel and emulsion muckpiles were carried out in close collaboration with mine operations. After each shot, the post-blast mark-up of areas to be monitored was done in coordination with short term planning, operation and dispatch areas. Digging cycle videos were taken from all loading and hauling operation in order to measure not only the instantaneous digging but the overall loading cycle. 

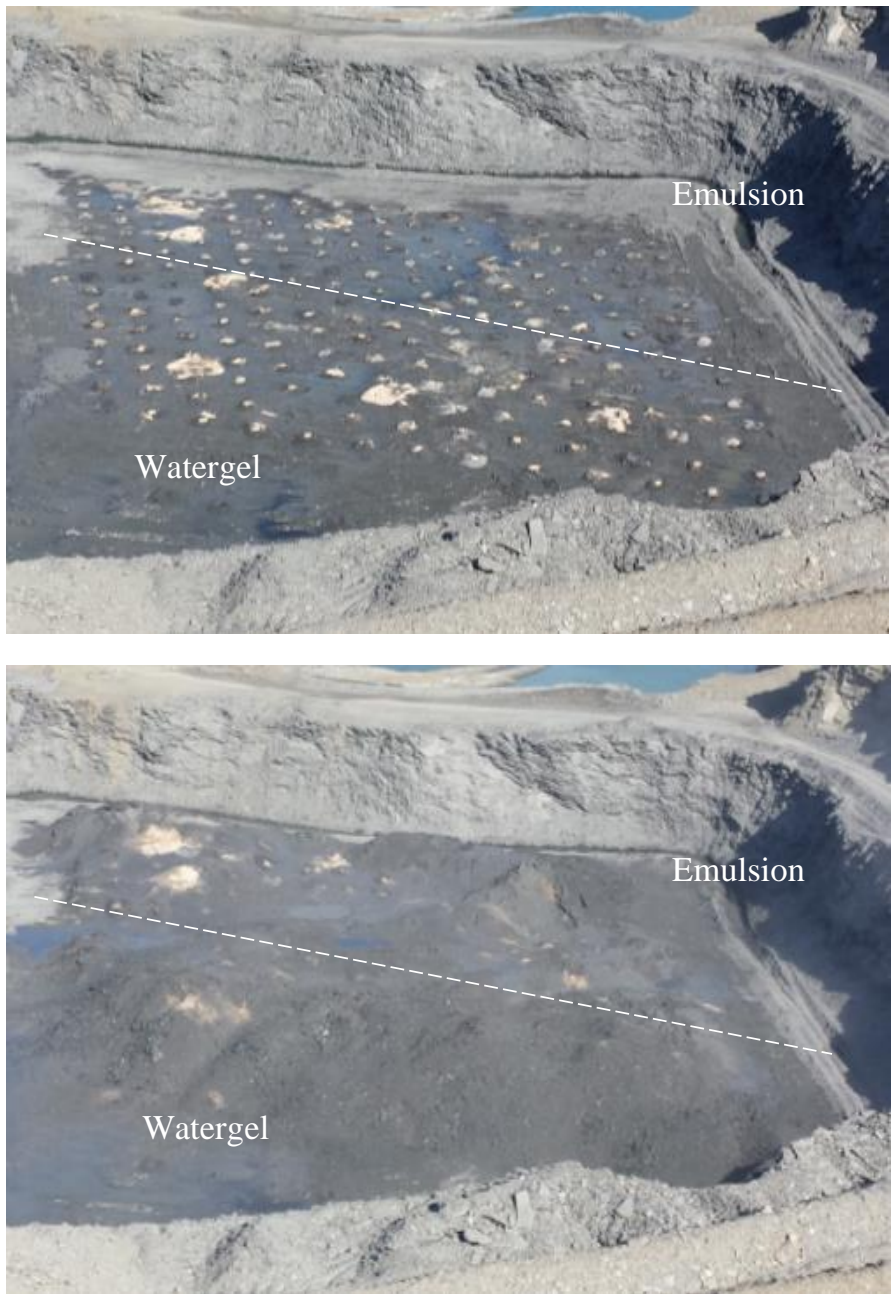

Fig. 1. Side by side blast comparison. Higher swelling from the watergel can be observed.

\section{A. Fragmentation measurements}

The fragmentation analysis was carried out with photometric techniques. The operation is illustrated in Figure 2. Several pictures were taken while the truck was loading and processed afterword by specific software such as Split-desktop and Wipfrag. The complete fragmentation curve was obtained from each shot, given the uniformity of the pile and particle size distributions. However, the P80 size was selected as the fragmentation KPI, since it was a requirement of the mine.

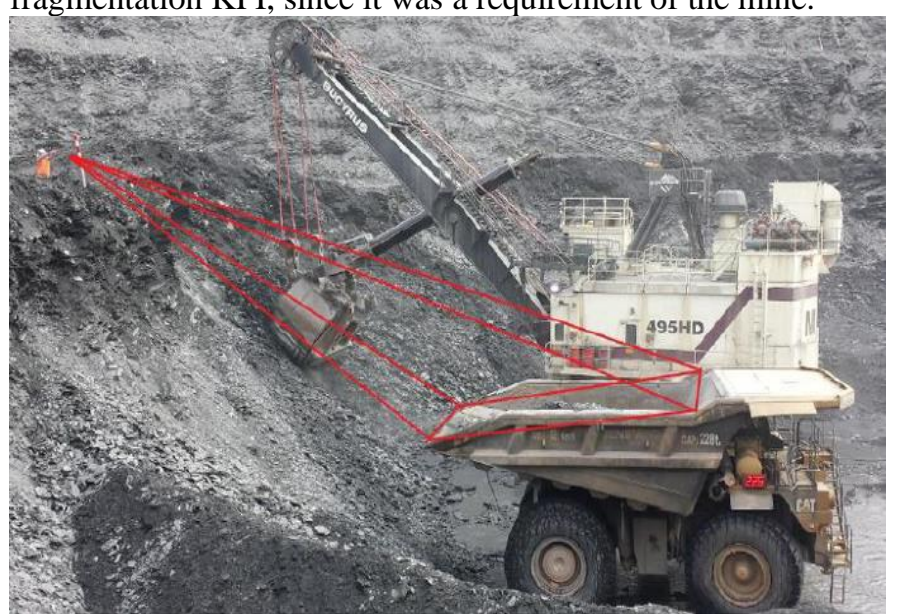

Fig. 2. Fragmentation analysis process by photometric technique. Pictures were taken while trucks were loading.

\section{B. Digging performance measurements}

The video analysis allows the time quantification of each step of the loading operation, such as bucket fill time, long sticking, dump bucket, swing back, truck wait, spot delay, reposition, clean-up and other delays. Among these, the bucket fill time is what really is affected by the blast results, usually referred as instantaneous digging. Figure 3 shows an example of a set of measurements carried out between watergel and emulsion.

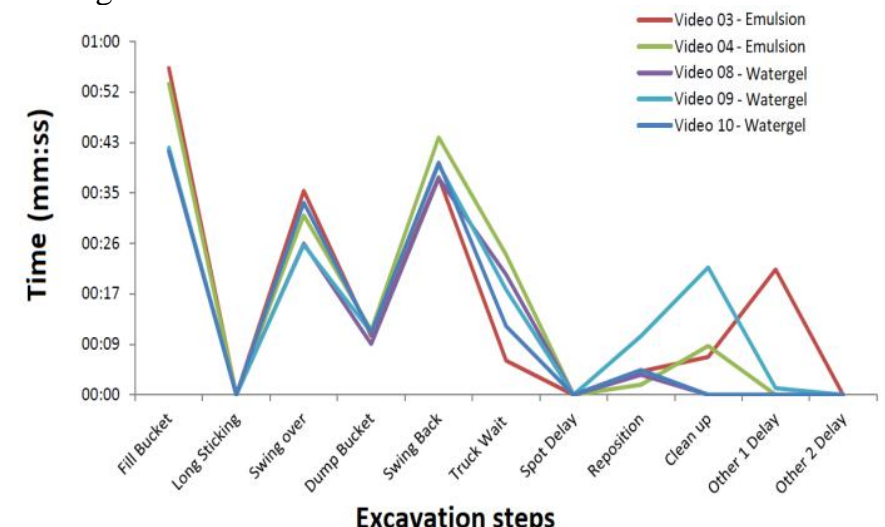

Excavation steps

Fig. 3. Loading time evaluation

\section{RESULTS AND DISCUSSIONS}

The improvement over the P80 were consistent during all blasts, as shown in Table 1. In some blasts, the differences in terms of fragmentation were notable. This regularity was later observed in terms of digging productivity, since loading was first unit operation after blast. The average improvement over the P80 was $28.6 \%$.

TABLE I. TRIALS RESULTS

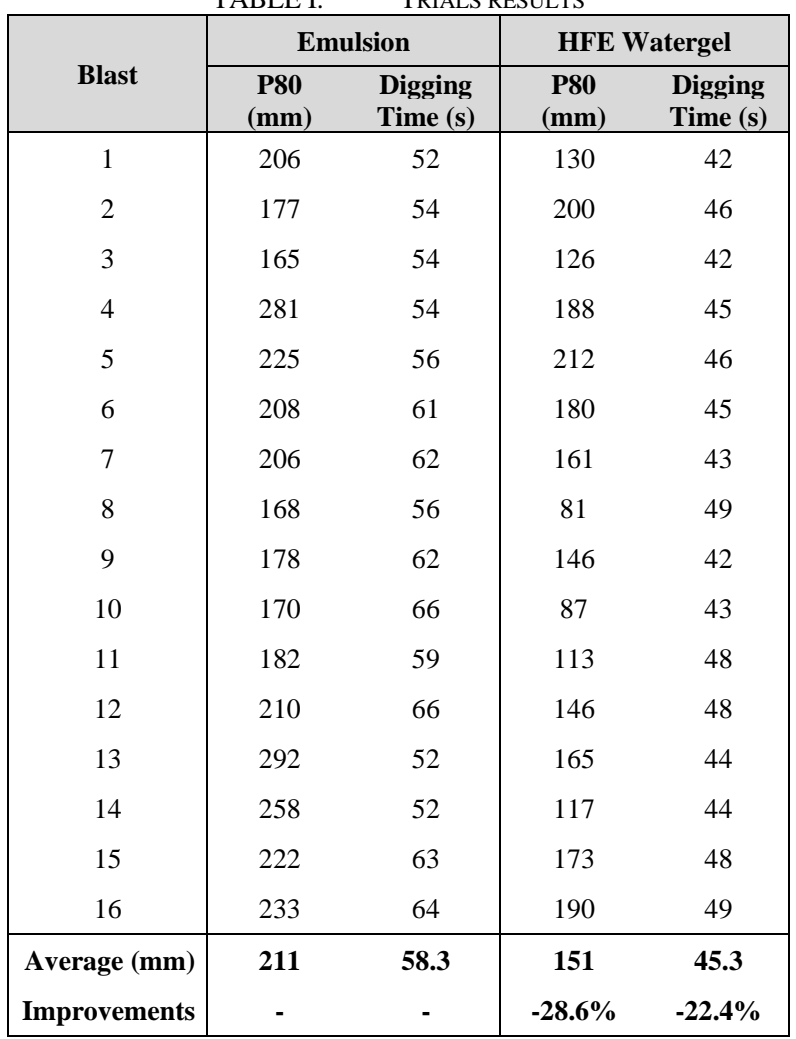


The analysis indicates a more expressive performance on the watergel muckpiles. In relation with the instantaneous digging rate, the bucket fill time presented an average reduction from $58.31 \mathrm{~s}$ with traditional emulsion to $45.3 \mathrm{~s}$ with watergel, a reduction of $22.4 \%$. The Figure 4 shows the average, minimum and maximum bucket fill times for watergel and emulsion. In terms of total loading cycle, the muckpiles were also more productive, leading a reduction of $17.8 \%$ in the total time.

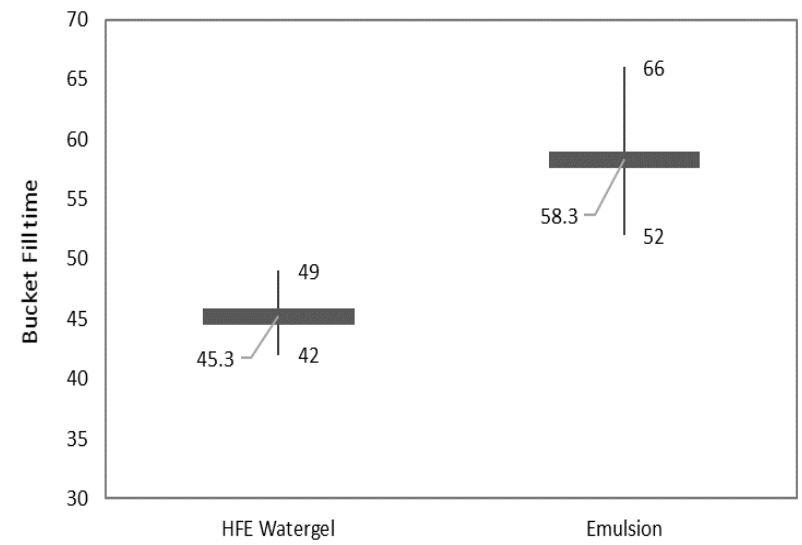

Fig. 4. Average bucket fill time with their maximum and minimum values.

These results were a consequence of an improved fragmentation and better muckpile's shape generated by watergel blasts. The swelling effect in these muckpiles were consistently higher than in the emulsions sectors. The use of high energetic explosive favored the achievement of such results. Additionally, all these improvements were achieved without disturbing the current levels of environmental issues, such as ground vibrations, noise, fumes, dust and fly-rocks.

\section{A. Bucket fill time model}

Based on the experimental data, a relationship between the energy factor and the bucket fill time was created. It relates the amount of energy per ton in the blast with the performance of the loading operation, as shown in figure 5. According to the statistical results, the correlation coefficient was $\mathrm{R}^{2}=$ 0.612. The scatter in the analysis is expected since more parameters than the energy factor is affecting the operation, which is not included in this work, such as the rock hardness, filling factor of the excavator's bucket, the muckpile's angle of response, and others.

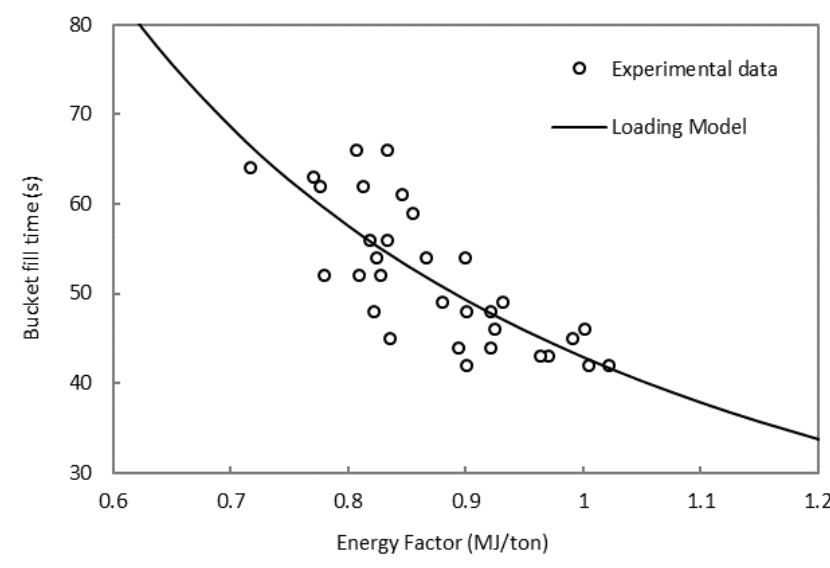

Fig. 5. Bucket fill time versus the blast energy factor.
Thus, the prediction of the loading performance can be estimated by the following mathematical relationship

$$
B c=42.87\left(E_{f}\right)^{-1.318}
$$

where $B c$ is the bucket fill time (s); $E_{f}$ is the blast energy factor $(\mathrm{MJ} /$ ton $)$.

Figure 6 shows the measured and calculated bucket fill time values. Although some scatter is present, the residuals are normally distributed according to the Shapiro-Wilk Test, with p-value of 0.699386
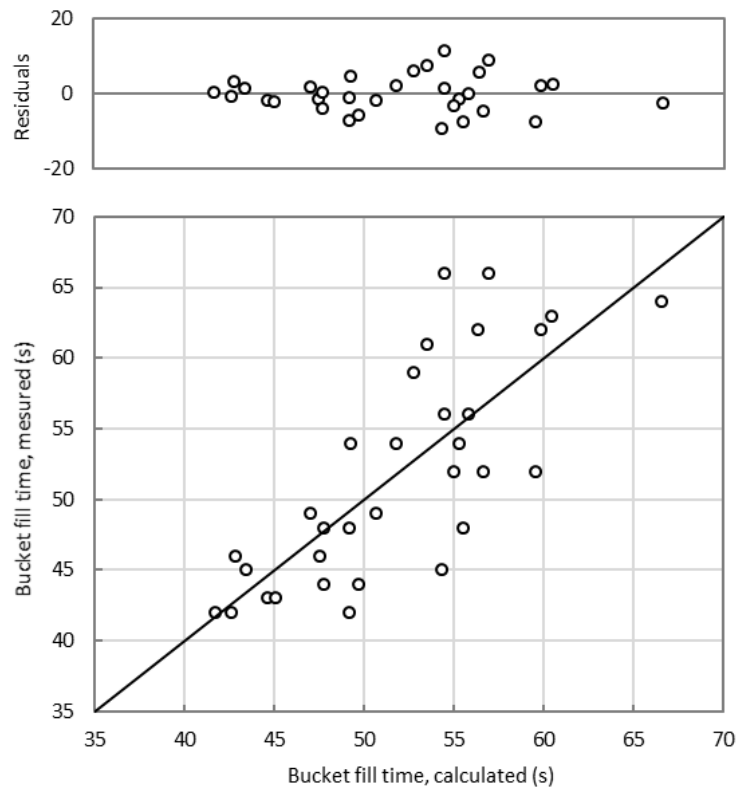

Fig. 6. Relation between estimated and measured times, and corresponding residuals.

\section{CONCLUSIONS}

This work shows some evidences on how the energy factor, and thus the blasting results, affects bucket loading times. Despite of all complexities involved in the loading and haulage operations, blasting results strongly contributes to reduce the total loading time and thus cycle period of excavators. This reinforce the use of the production rate of the excavators as a good indicator of the blast performance. Thus, a simple mathematical model to estimate the bucket fill time in function of the blast energy factor was presented based on the data from an important South America gold mine.

\section{REFERENCES}

[1] S. Hawke and L. Dominguez, "A Simple Technique for Using High Energy in Blasting", In: Proc. 11th International Symposium on rock fragmentation by blasting, Sydney. Australia., 2015.

[2] P. Segarra, A. Sanchidrían, L. Lopez and E. Querol, "On the Prediction of Mucking Rates in Metal Ore Blasting", Journal of Mining Science, Vol. 46, No.2., 2010.

[3] K. Ozdemir, G. Tuncer, A. Kahriman, U. Ozer and A. Karadogan, "The Relation between Excavator Bucket Loading Time and Particle Size Distribution", In: Proc 33th Ann Conf on Explo and Blast Tech. ISEE. USA., 2007.

[4] S. Singh, R. Narendrula and D. Duffy, "Influence of Blasted Muck on the Performance of Loading Equipment", In: Proc 3rd EFEE World Conference on Explosives and Blasting, Brighton, UK, 2005.

[5] M. Doktan, "Impact of Blast Fragmentation on Truck Shovel Fleet Performance", 17th International Mining Congress and Exhibition of Turkey, IMCET2001, 2001.

[6] S. Chung and D. Preece, "Explosive energy and muckpile diggability", In: Proc. of the 25th Annual Conf. on Explosives and Blasting Technique, Nashville, Tennessee, 1999. 
[7] I. Brunton, D. Thornton, R. Hodson and D. Sprott, "Impact of blast fragmentation on hydraulic excavator dig time", In: Proc. of the 5th Large Open Pit Conf., Kalgoorlie, Australia , 2003.

[8] C. Hendricks, J. Peck and M. Scoble, "Integrated drill and shovel performance monitoring towards blast optimization", In: Proc. of the 3rd Int. Symp. on Rock Fragmentation by Blasting, Brisbane, Australia, 1990.

[9] C. McKenzie, P. Geddes, K. Grohs and M. Morrish, "Blasting trials to control and monitor displacement of narrow vein gold ore", In: Proc. of the 24th Annual Conf. on Explosives and Blasting Technique, New Orleans, Louisiana, 1998 